\title{
Policy Responses to the Economic Crisis - Investing in Innovation for Long Term Economic Growth
}

The current crisis is the first of this severity to hit the 30 OECD member countries since they shifted to knowledge-based economies where investment in intangible assets is or equal importance as investment in machinery, equipment and buildings. Innovation will be one of the keys to emerging from the current crisis, but it risks being it hard by the downturn. This is a major conclusion of a new report prepared by the OECD: Policy Responses to the Economic Crisis - Investing in Long-Term Growth. (www.oecd.org).

Efforts to stimulate economies should involve innovative policies toward structural shifts to service-related industries - this should influence how such policies are crafted to work but also as elements of stimulus packages that may often be the foundation for these medium and long-term initiatives.

The economic crisis has already begun to affect innovation - because historically, business R\&D expenditures and patent filings have moved in parallel with GDP, slowing markedly during economic downturns in the early 1990s and early 2000s. R\&D is declining because it is mainly financed from cash flow (retained earnings) which contracts in downturns.

At the same time, as banks and investors have become more risk averse, firms face difficulties in tapping into external sources of funding (there is a decline in foreign direct investment) to support their investments in $\mathrm{R} \& \mathrm{D}$. Business $\mathrm{R} \& \mathrm{D}$ is also being re-oriented towards short-term, low-risk innovations, while longer term, high risk innovation projects are being cut first.

SMEs in most countries are now confronted with a clear downturn in demand for goods and services if not a demand slump, crimping cash flow. Many SMEs are faced with problems (1) increased payment delays in receivables and (2) an increase in reported defaults, insolvencies and bankruptcies.

However, the crisis can magnify the competitive advantage of research-intensive firms who seize the opportunity to reinforce market leadership through increased spending on innovative R\&D.

\section{Crisis Should be Springboard to Accelerate Shifts for Long-Term Economic Growth}

The economic crisis has prompted immediate response by governments to avoid a collapse of the financial and bank systems and limit the economic effects of the credit crunch. Such policies aim at stabilizing the economy and initiating a rapid recovery. But policies also need to ensue that the recovery is durable, i.e. based on sustainable growth. The crisis should not damage the drivers of long-term growth, but should instead be used as a springboard to accelerate structural shifts toward a stronger, fairer and cleaner economic future. Failing to do so might lead only to a temporary recovery as the macro-economic and structural roots of the current downturn would remain untouched. This implies integrating long term concerns in the short term policy packages currently assembled by governments and implementing specific policies aimed at strengthening the supply-side of the economy.

While the impact of some of the latter actions may emerge in the medium- to long-term, they warrant consideration now because: (1) they add credibility to government's borrowing demands that are imposing longterm debt, thus making a contribution to fiscal sustainability and (2) they take advantage of structural change 
imposed by the crisis to accelerate a redeployment of resources from ailing activities to those that offer the largest longer term economic and social benefits.

The foundation of these medium- longer-term initiatives consist of: fostering innovation through promoting entrepreneurship, investing in smart infrastructure, encouraging $R \& D$, green investment, upgrading the skills of workers, steering market actors towards innovation-related investments, and accelerating activities for which barriers may have been too high otherwise. The crisis is affecting innovation and a number of other determinants of long-term growth.

\section{Investments in innovation are declining in many firms}

The available evidence suggests that the crisis has already begun to affect innovation. Historically, business $R \& D$ expenditure and patent filings have moved in parallel with GDP, slowing markedly during economic downturns of the early 1900 s and of the early 2000 s. Data on trademark filings, that reflect the creation of new goods or services, with or without technological content, shows that the business cycle is affecting a wide range of innovation.

$\mathrm{R} \& \mathrm{D}$ is declining because it is mainly financed from cash flow (retained earnings) which contracts in downturns. At the same time, as banks, markets and investors have become more risk averse; firms face difficulties in tapping into external sources of funding to support their investments in R\&D. Business R\&D is also being re-oriented towards short-term, low risk innovations, while longer term, high risk innovation projects are being cut first. The decline in business R\&D risks affecting the stock of knowledge as highly trained researchers and innovators lose their jobs. Small, innovative firms are particularly are hit because in many cases their primary asset is intangible in nature (e.g. an idea or patent) and difficult to value, making it hard to borrow against, or sell, to stay afloat.

The crisis can, however, magnify the competitive advantage of research-intensive firms who seize the opportunity to reinforce market leadership through increased spending on innovation and R\&D. Many of today's leading firms such as Microsoft and Nokia were born or transformed in the "creative destruction" of economic downturns. And several of today's leading technology firms, such as Samsung Electronics, or Google strongly increased their R\&D expenditures during and after he "new economy" bust of 2001.

\section{The crisis is affecting entrepreneurship and business dynamics}

Economic crises are historically times of renewal. Less efficient firms fail while more dynamic ones emerge and expand. Creative destruction is an essential engine of long term efficiency in market economies, and it intensifies in downturns. Available data for many OECD countries point to a sharp increase in bankruptcies and business failures in recent months. New business models and new technologies, particularly those allowing a deduction in cost, often arise in downturns, as was the case with low-cost airlines which grew out of the recession of the early 1990s. As dominant players weaken, they open space for new players and innovators.

However, economic downturns can have a detrimental effect on the creation of new, innovative businesses when access o financing dries up. The key role of finance in the development of small and medium-sized enterprises (SMEs) is illustrated by Finland where the peak in financial constraints coincided closely with the deep recession of the early 1990s and a downturn in self-employed. Economic growth suffers doubly in the long term since innovative new firms exert competitive pressure on established firms pushing them to innovate. Barriers to entry are higher during downturns: studies for the United States, for example, show that fewer manufacturing firms enter during recession, and that these firms are (on average) larger and more efficient than firms created during strong expansion phases.

SMEs in most OECD countries are now confronted with a clear downturn in demand for goods and services if not a demand slump, crimping cash flow. And many SMEs are faced with two additional problems: (1) increased payment delays on receivables which add together with an increase in inventories, to an endemic shortage of working capital and a decrease in liquidity; and (2) an increase in reported defaults, insolvencies and bankruptcies.

\section{Plummeting international trade is affecting global value chains, an important source of innovation}

The sharp decline in trade, foreign direct investment and access to international financing, poses a risk to the global supply chains that underpin innovation. These supply chains are critical sources of new knowledge and learning. They provide companies with technical 
expertise, knowledge of foreign markets, critical business contacts and international partners. The current decline of trade and investment flows could have severe consequences for these knowledge transfers and for innovation at a global level. Trade is not at the origin of the crisis, but since it binds economies closely together, it helps to spread developments from one country to another - the negative developments as well as the positive.

The risks to global value chains emerge not only from the decline in international trade, but also from key suppliers facing bankruptcy, and from firms reconsidering their investment strategies and retrenching to core markets. Protectionist policies could exacerbate these risks. It would increase the input costs for domestic industries and would penalize exporters twice, through higher costs and through retaliation from other countries.

Firms now rely on a global business model, and retrenchment risks disrupting international links, affecting growth and future innovation in both OECD countries and non-OECD economies. Coordination of government actions can help address these risks, can produce a more effective, longer-lasting solution and can also result in positive spill-over effects. 